\title{
Pulsed Laser Micro Polishing: Surface Prediction Model
}

\author{
Madhu Vadali ${ }^{1}$, Chao $\mathrm{Ma}^{2}$, Neil A. Duffie ${ }^{3}$, Xiaochun $\mathrm{Li}^{4}$, and Frank E. Pfefferkorn ${ }^{5,}$ \\ ${ }^{1}$ Madhu Vadali; Mechanical Engr., University of Wisconsin - Madison; e-mail: vadali@wisc.edu \\ ${ }^{2}$ Chao Ma; Mechanical Engr., University of Wisconsin - Madison; e-mail: cma25@wisc.edu \\ ${ }^{3}$ Neil A. Duffie; Mechanical Engr., University of Wisconsin - Madison; e-mail: duffie@engr.wisc.edu \\ ${ }^{4}$ Xiaochun Li; Mechanical Engr., University of Wisconsin - Madison; e-mail: xcli@engr.wisc.edu \\ ${ }^{5}$ Frank E. Pfefferkorn; Mechanical Engr., University of Wisconsin - Madison; e-mail: pfefferk@engr.wisc.edu
}

\begin{abstract}
This project is focused on developing physics-based models to predict the outcome of pulsed laser micro polishing $(\mathrm{PL} \mu \mathrm{P})$. Perry et al. [1-3] have modeled PL $\mu \mathrm{P}$ as oscillations of capillary waves with damping resulting from the forces of surface tension and viscosity and a one-dimensional spatial frequency domain analysis was proposed. They have also proposed a critical spatial frequency, $\mathrm{f}_{\mathrm{cr}}$, above which a significant reduction in the amplitude of the spatial Fourier components is expected. The current work extends the concept of critical frequency to two dimensional spatial frequency analysis of PL $\mu \mathrm{P}$. We propose a physics-based prediction methodology to predict the spatial frequency content and surface roughness after polishing, given the features of the original surface, the material properties, and laser parameters used for PL $\mu \mathrm{P}$.
\end{abstract}

The proposed prediction methodology was tested using $\mathrm{PL} \mu \mathrm{P}$ line polishing data for stainless steel $316 \mathrm{~L}$ and area polishing results for pure Nickel, Ti6Al4V, and Al-6061-T6. The predicted average surface roughnesses were within $10 \%$ to $12 \%$ of the values measured on the polished surfaces. The results show that the critical frequency continues to be a useful predictor of polishing results in the 2-D spatial frequency domain. The laser processing parameters, as represented by the critical frequency, and the initial surface texture can be used to predict the final surface roughness before actually implementing PL $\mu \mathrm{P}$.

\section{INTRODUCTION}

Perry et al. [1-3] have demonstrated that pulsed laser micro-polishing (PL $\mu \mathrm{P})$ with pulse durations of 300-650 ns and a spot size of $60 \mu \mathrm{m}$ is a method by which the surface roughness of microfabricated and micro milled parts can be effectively reduced. Improved surface finish and smoothness can be achieved on select areas of different metallic surfaces, produced by meso/micro-manufacturing processes, which is difficult via other methods (like mechanical polishing, electropolishing and chemical mechanical polishing) as the feature sizes are approaching the same magnitude as the surface roughness [4-8]. Past research on laser induced surface modification and surface finish also indicate that reduction surface is also possible at pulse durations less than 200 ns and spot sizes of few hundreds of microns.[9, 10]. Most recent research includes laser induced surface finish of titanium for bio-implants $[11,12]$ and micro-roughness reduction of tungsten films in the IC industry[13].

In PL $\mu$ P, laser pulses irradiate the surface. Each pulse results in melting followed by damped oscillations of the melted surface due to the forces of surface tension and viscosity. If the oscillations damp out within the time that the surface is molten, a smoother surface will result upon solidification $[16,17]$. Analytical models were proposed to describe the dynamics of the melt pool [10-12]. These models are based on spatial Fourier analysis of the surfaces and examination of Navier-Stokes equation for each Fourier component. In the present work, we extend these analytical models and numerical models of Perry et al. [1-3] to two dimensions and use the same to predict the surface finish, given the initial surface conditions.

Perry et al. [1-3] have proposed a critical frequency, $\mathrm{f}_{\mathrm{cr}}$, which describes the cutoff point in the spatial frequency content of the surface, above which a significant reduction in the amplitude is expected. The critical frequency is a function of the duration of the molten state. Experimental studies using a variety of materials (stainless steel $316 \mathrm{~L}$, nickel, Ti6Al4V and Al-6061-T6), initial surface roughness (70-190 $\mathrm{nm}$ ) and pulse durations (300 to $5000 \mathrm{~ns}$ ) have confirmed the ability of the critical frequency to predict which surface features (asperities) will experience significant reductions in amplitude, i.e., polishing.

In the current work, we aim to (1) extend the concept of the critical frequency to 2-D spatial frequency analysis and (2) use it to predict the polished surface topography and roughness resulting from PL $\mu \mathrm{P}$. The ability to predict the two-dimensional surface topography and roughness of the polished surface is expected to be a significant tool in the selection of laser parameters based on the requirements of the final surface. Experimental results are presented that allow predicted surface spatial frequency content and roughness to be compared with empirical surface spatial frequency content and roughness for micro end milled surfaces on three different metals: nickel, Ti6A14V and Al-6061-T6.

\section{PROCESS MODEL}

Predicting the outcome of PL $\mu$ P requires a model of how the surface behaves when it is molten. This has been accom- 
plished by integrating an analytical fluid flow model and a numerical heat transfer model.

\section{A. FLUID FLOW MODEL}

When a laser pulse of sufficient energy is incident on a surface, the surface asperities and some depth of metal below the surface melt. The molten asperities (i.e., roughness features) become regions of high surface tension because of their smaller radius of curvature. These molten asperities have small amplitude to wavelength ratios and can be modeled as capillary waves. The surface tension forces acting on these molten asperities introduce sinusoidal oscillations on the surface, and the amplitude of these oscillations will decay due to viscosity. In the current model, it is assumed that these oscillations correspond to standing waves. Gravity forces can be neglected at these scales.

2-D spectral analysis techniques are used to model the geometry of the surface [18]. The surface is transformed into the corresponding spatial Fourier components that are used in modeling. Landau and Lifshitz [19] have shown that the amplitude, $\zeta$, of a spatial frequency component decays exponentially with time:

$$
\zeta(\mathrm{t})=\zeta(0) e^{-\gamma \mathrm{t}}
$$

where, $\gamma$, the coefficient of damping, for a given Fourier component of wave number $\kappa$ is

$$
\gamma=\frac{2 \mu \kappa^{2}}{\rho}
$$

where, $\mu$ is the dynamic viscosity and $\rho$ is the density. The wave number, $\kappa$, can be expressed in terms of spatial frequencies, $\mathrm{f}_{x}$ and $\mathrm{f}_{y}$, as

$$
\kappa=2 \pi\left(\mathrm{f}_{x} \boldsymbol{i}+\mathrm{f}_{y} \boldsymbol{j}\right)
$$

The amplitude of interest in PL $\mu \mathrm{P}$ is the amplitude of a spatial frequency component at the surface of the melt pool at the maximum melt duration, $t_{m-m a x}$. Therefore, Eq. (1) can be rewritten as

$$
\zeta\left(\mathrm{t}_{\mathrm{m}-\mathrm{max}}\right)=\zeta(0) \mathrm{e}^{-\gamma \mathrm{t}_{\mathrm{m}-\mathrm{max}}}
$$

which gives the final amplitude for a given spatial frequency component. Using Eqs. (2) and (3), this result can be generalized for all spatial frequencies, $\mathrm{f}_{x}$ and $\mathrm{f}_{y}$, as

$$
\zeta\left(\mathrm{f}_{x}, \mathrm{f}_{y}\right)_{\text {polished }}=\zeta\left(\mathrm{f}_{x}, \mathrm{f}_{y}\right)_{\text {unpolished }} e^{-\gamma\left(\mathrm{f}_{x}, \mathrm{f}_{y}\right) \mathrm{t}_{\mathrm{m}-\mathrm{max}}}
$$

where,

$$
\gamma\left(\mathrm{f}_{x}, \mathrm{f}_{y}\right)=\frac{8 \pi^{2} \mu\left(\mathrm{f}_{x}^{2}+\mathrm{f}_{y}^{2}\right)}{\rho}
$$

Perry et al [1-3] have shown that knowledge of the maximum melt duration, $t_{m-\max }$, can be used to determine the minimum critical frequency, $\mathrm{f}_{\mathrm{cr}}$, above which there should be a significant reduction in amplitude of the spatial frequency content of a surface and its asperities. The critical frequency is

$$
\mathrm{f}_{\mathrm{cr}}=\left(\frac{\rho}{8 \pi^{2} \mu \mathrm{t}_{\mathrm{m}-\mathrm{max}}}\right)^{\frac{1}{2}}
$$

The melt pool is assumed to axisymmetric, hence the critical frequency is assumed to be identical in the $x$ and $y$ directions. Using Eqs. (5), (6) and (7), the amplitude of the surface at spatial frequency $\mathrm{f}_{x}$ and $\mathrm{f}_{y}, \zeta\left(\mathrm{f}_{x}, \mathrm{f}_{y}\right)$, after solidification (i.e., at the end of $t_{m-\max }$ ) can be predicted using

$$
\zeta\left(\mathrm{f}_{x}, \mathrm{f}_{y}\right)_{\text {polished }}=\zeta\left(\mathrm{f}_{x}, \mathrm{f}_{y}\right)_{\text {unpolished }} e^{-\left[\left(\mathrm{f}_{x} / \mathrm{f}_{\mathrm{cr}}\right)^{2}+\left(\mathrm{f}_{y} / \mathrm{f}_{\mathrm{cr}}\right)^{2}\right]}
$$

This is a special case of a low-pass Gaussian filter, and prediction of the final surface can be viewed as a filtering process with the break frequency at the critical frequency. Note that the mathematics behind 2-D spectral analysis (2-D Fourier analysis) results in spectral content corresponding to negative frequencies. Physically, these negative spatial frequencies have no significance. Hence, all further discussion will be confined to positive spatial frequencies in both $x$ and $y$ directions. Fig. 1 illustrates the spatial filter confined to the positive frequencies.

With knowledge of the spatial frequency content of the surface before polishing and an estimate of the critical frequency obtained from Eq. (7), Eq. (8) can be used to predict the spatial frequency content of the laser polished surface. The average surface roughness can then be calculated from the predicted surface profile. Determining the critical frequency requires an estimate of the maximum melt duration. A transient, two-dimensional axisymmetric heat transfer model of pulsed laser melting has been developed for this purpose.
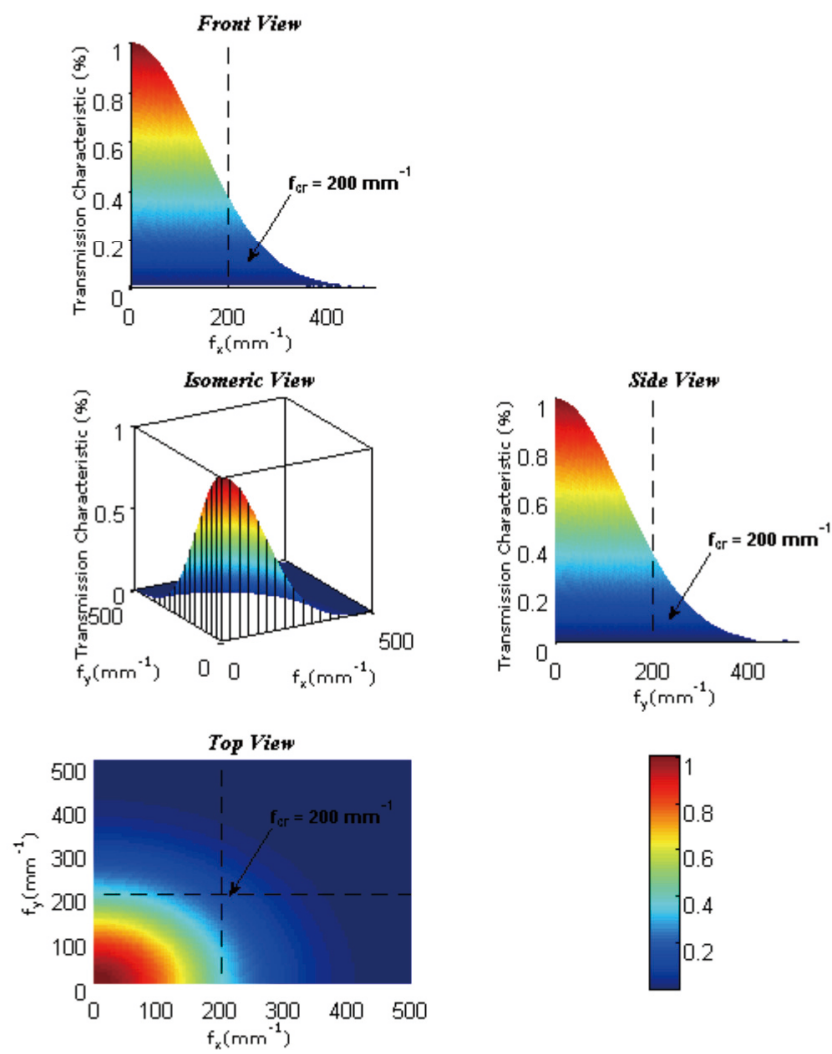

Fig. 1: First quadrant (positive spatial frequencies) section of a typical 2-D low pass filter described in Eq. (8). 


\section{B. HEAT TRANSFER MODEL}

Perry et al. [1-3] used a one-dimensional finite element model to simulate melting due to a single laser pulse in which it was assumed that [20]

$$
\chi t_{\text {pulse }}<<r^{2}
$$

where $\chi$ is the thermal diffusivity, $\mathrm{t}_{\text {pulse }}$ is the laser pulse duration, and $\mathrm{r}$ is the laser spot radius. The ability of this one-dimensional model to accurately estimate $t_{\mathrm{m} \text {-max }}$ diminishes at higher pulse durations. Therefore, a transient, two-dimensional axisymmetric model was developed. To simplify the model, polishing was assumed to occur in an inert atmosphere, the workpiece was assumed to be homogenous and isotropic, reflectivity of the melt was not considered, convection and radiation were assumed to be negligible, and the initial temperature of the workpiece was assumed to be room temperature: $298 \mathrm{~K}$.

The physical properties of stainless steel 316L, Nickel, Ti6A14V and Al-6061-T6 [21] used in the finite element analysis software (ANSYS) include enthalpy change $\Delta H$ and thermal conductivity $\mathrm{k}$. The properties of stainless steel $316 \mathrm{~L}$ were not available in the literature hence the properties of stainless steel 316 were used. Considering the phase change in the melting process, the total enthalpy change $\Delta H$ was represented by a sum of sensible heat $\Delta \mathrm{h}$ and latent heat content $\Delta \mathrm{L}$, i.e., $\Delta \mathrm{H}=\Delta \mathrm{h}+\Delta \mathrm{L}$ [22]. The sensible heat $\mathrm{h}$ can be expressed as $\Delta \mathrm{h}=\int_{298}^{\mathrm{T}} \mathrm{C}_{\mathrm{p}} \mathrm{dT}$, where $\mathrm{C}_{\mathrm{p}}$ is the specific heat and $\mathrm{T}$ is the temperature. The latent heat content $\Delta \mathrm{L}$ is given as $\Delta \mathrm{L}=\mathrm{L} \cdot \mathrm{F}_{\mathrm{L}}$, where $\mathrm{L}$ is the latent heat of melting. The liquid fraction $\mathrm{F}_{\mathrm{L}}$ was assumed to vary linearly with temperature [22]:

$$
\mathrm{F}_{\mathrm{L}}=\left\{\begin{array}{cc}
1 & \mathrm{~T}>\mathrm{T}_{\mathrm{L}} \\
\frac{\mathrm{T}-\mathrm{T}_{\mathrm{S}}}{\mathrm{T}_{\mathrm{L}}-\mathrm{T}_{\mathrm{S}}} & \mathrm{T}_{\mathrm{S}} \leq \mathrm{T} \leq \mathrm{T}_{\mathrm{L}} \\
0 & \mathrm{~T}<\mathrm{T}_{\mathrm{S}}
\end{array}\right.
$$

where $T_{L}$ and $T_{S}$ are the liquidus and solidus temperatures, respectively. However, pure Nickel does not change phase over a range of temperatures: i.e., liquidus $=$ solidus $=$ melting temperature. This results in a rapid increase in enthalpy as the temperature increases during phase change, which in turn can cause convergence problems in numerical solutions. To accommodate this nonlinearity, an arbitrary solidification range of $6 \mathrm{~K}$ was introduced [23], which is $0.3 \%$ of the melting temperature.

The heat flux incident on the workpiece was modeled as spatially uniform (flat top) and Gaussian in the time domain. The laser pulse duration was defined as full width at half maximum (FWHM) of the Gaussian function.

\section{PREDICTION METHODOLOGY}

The proposed method for surface profile and roughness prediction is shown in Fig. 2 and consists of the following steps:

Step 1: Initial surface data acquisition and pre-processing
The first step is to obtain the surface height data of the initial (unpolished) surface using an appropriate measurement technique. In the current work, all surface measurements were made using a white-light interferometer $\left(\mathrm{Zygo}^{\circledR}\right.$ NewView ${ }^{\mathrm{TM}}$ 6300). The interferometry technique also captures the surface curvature/form. Least squared error method was used to compute the mean plane from the surface height data and was removed.

\section{Step 2: Estimation of process parameters}

The two process parameters required for the prediction model are the maximum melt duration, $t_{m-\max }$ and the critical frequency, $\mathrm{f}_{\mathrm{cr}}$. The two-dimensional axisymmetric heat transfer model described above was used to numerically estimate the maximum melt duration. Using this result and Eq. (7), the critical frequency was predicted. The physical parameters used are listed in Table 1.

Table 1: Physical properties of stainless steel 316, nickel, Ti6Al4V, 6061-T6 and aluminum[21]

\begin{tabular}{ccc}
\hline \hline Material & $\begin{array}{c}\text { Dynamic Viscosity, } \mu \\
(\mathrm{mPa} . \mathrm{s})\end{array}$ & $\begin{array}{c}\text { Density, } \rho \\
(\mathrm{kg} / \mathrm{m} 3)\end{array}$ \\
\hline $\begin{array}{c}\text { Stainless Steel } \\
316\end{array}$ & 8.00 & 6881 \\
Nickel & 4.70 & 7850 \\
Ti6A14V & 3.23 & 3917 \\
Al-6061-T6 & 1.15 & 2415 \\
\hline \hline
\end{tabular}

\section{Step 3: Spatial domain filtering}

This step involves predicting the spatial frequency spectrum of the polished surface using the spatial frequency spectrum of the initial unpolished surface. The unpolished spatial frequency spectrum was computed using two dimensional Fast Fourier analysis of the digital surface height data, and the low pass spatial filter described in Eq. (8) was applied. This gives the prediction of spatial frequency content of the polished surface.

\section{Step 4: Characterization of the predicted polished surface}

Roughness average, $\mathrm{S}_{\mathrm{a}}$, and root mean square (rms) roughness, $\mathrm{S}_{\mathrm{q}}$, and were computed [24]. The surface height data, $\mathrm{Z}(x, y)$, is obtained by inverse Fourier transformation of the predicted polished surface spatial frequency content.

\section{EXPERIMENTAL METHODS AND SETUP}

The accuracy of the prediction methodology was compared to a variety of experimental data sets. In the current paper, prediction results on four materials: stainless steel 316L, Nickel, Ti6Al4V and Al-6061-T6, are reported and are compared to the actual PL $\mu \mathrm{P}$ results. The experimental surfaces on stainless steel $316 \mathrm{~L}$ and Ti6Al4V were produced using micro end milling while the surfaces on Nickel and $\mathrm{Al}$ 6061-T6 were produced with abrasive media (i.e., 400, 600, 800 , and 1200 grit abrasive pads). These processes were chosen because they result in surface topographies with rich frequency content. 
The basic experimental setup is illustrated in Fig. 3. A 1064nm, 250 W (CW) Nd:YAG laser (Lee Lasers, Model: 8250MQ) was used for experimentation. The laser was directed by static mirrors into a scan head (ScanLab HurryScan $14 \mathrm{~mm}$ ) to allow for high-speed, two-dimensional scanning at beam velocities of up to $1.5 \mathrm{~m} / \mathrm{s}$. The scan head was controlled by a ForeSight control card from LasX Industries and had an f-theta objective (Linos f-theta-Ronar, Model: 4401-302-000-20/21) with a focal length of $100 \mathrm{~mm}$. A $\mathrm{z}$-axis manual stage was used to adjust the laser spot size (i.e., fluence incident on the sample) and to accommodate samples of varying thickness.

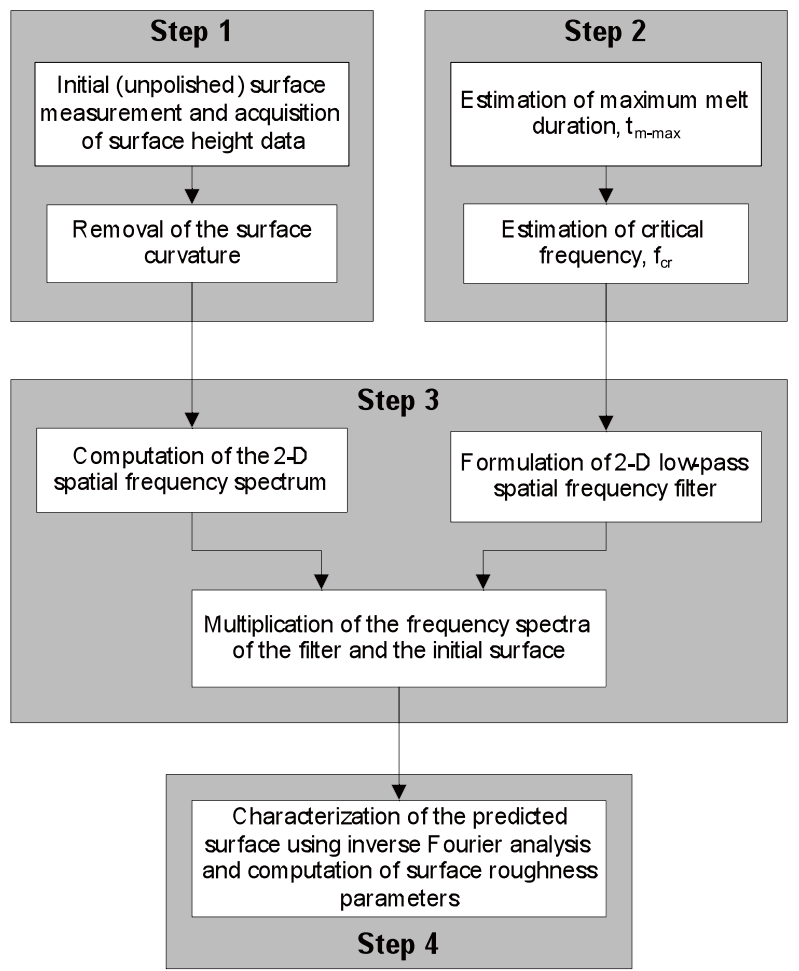

Fig. 2: PLHP surface prediction method

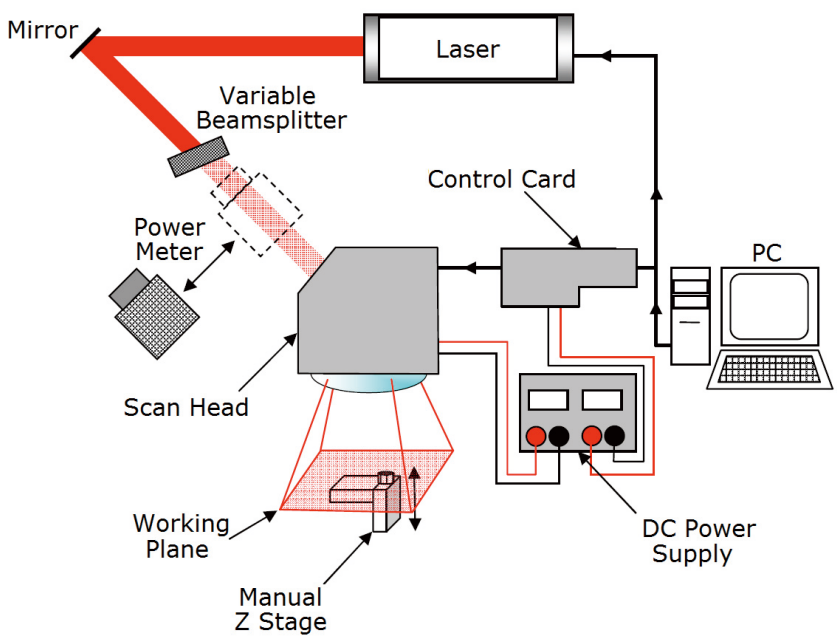

Fig. 3: Experimental setup

\section{RESULTS}

\section{A. LINE POLISHING RESULTS}

Initially, the prediction methodology was assessed using one-dimensional analysis. Line profile data of the rough unpolished surface was obtained from a micro end milled stainless steel $316 \mathrm{~L}$ sample using white-light interferometry. The average roughness, $\mathrm{R}_{\mathrm{a}}$, was calculated to be 183 $\mathrm{nm}$. PL $\mu \mathrm{P}$ was carried out using a $1070 \mathrm{~nm}$ wavelength, 50 $\mathrm{W} \mathrm{CW/modulated} \mathrm{fiber} \mathrm{laser,} \mathrm{producing} 5000 \mathrm{~ns}$ pulses. The melt duration was estimated to be $6820 \mathrm{~ns}$ and the critical frequency was found to be approximately $40 \mathrm{~mm}^{-1}$. Fig. 4 shows the surface model, and Fig. 5 shows the surface intensity map obtained using a white-light interferometer. PL $\mu \mathrm{P}$ reduced the average roughness to $84.7 \mathrm{~nm}$, while the proposed methodology predicted an $\mathrm{R}_{\mathrm{a}}$ of $76.6 \mathrm{~nm}$ after PL $\mu \mathrm{P}$.

Fig. 6 shows the spatial frequency spectra, obtained by Fourier transformation, of the polished and the unpolished line profile data from Fig. 5. Also shown is the filtered spatial frequency spectrum, which represents the frequency content predicted for the polished surface. The predicted spectrum compares well with the spectrum of the actual polished surface.

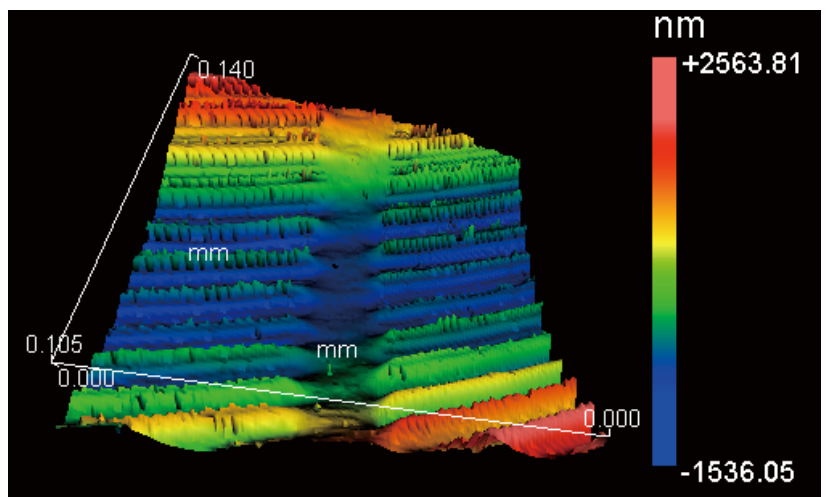

Fig. 4: Surface model of the polished stainless steel 316L sample

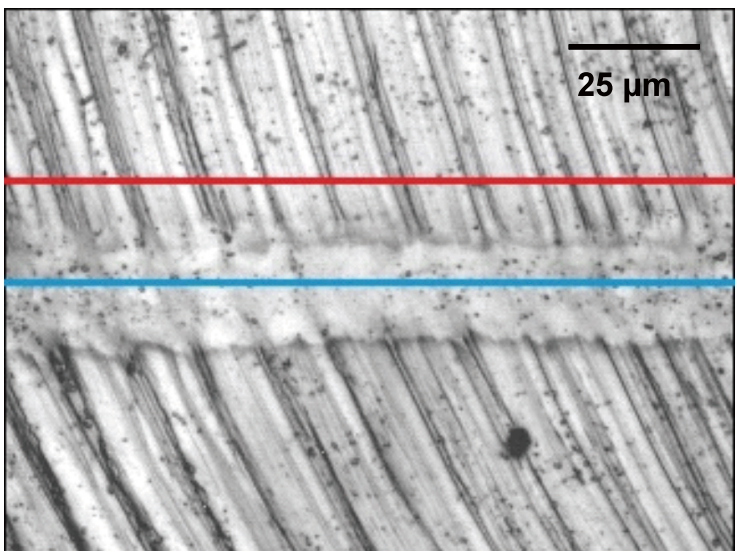

Fig. 5: Surface intensity map of stainless steel 316L sample with polished (blue) and unpolished (red) lines 


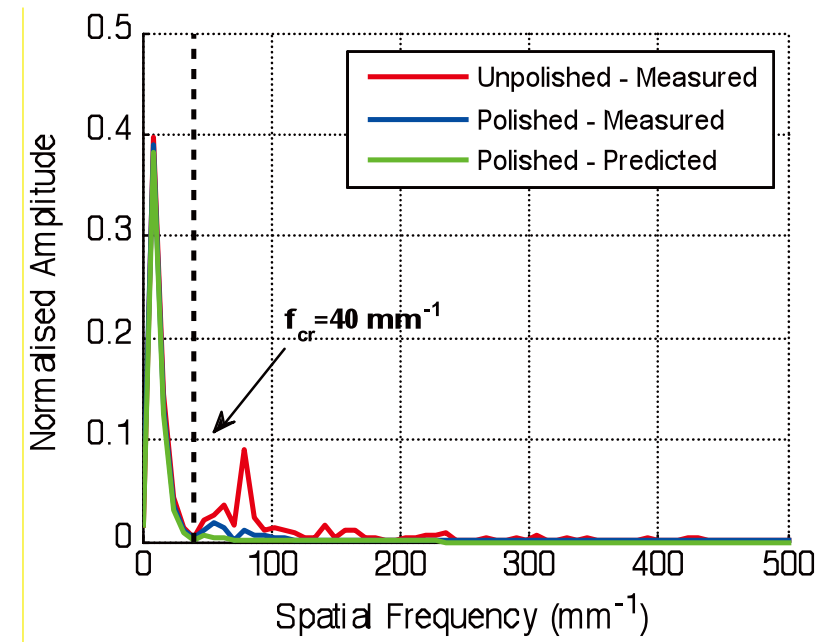

Fig. 6: Spatial frequency plots of the original (unpolished), actual (polished-measured) and predicted (polished-predicted) line profiles on stainless steel $316 \mathrm{~L}$ sample

\section{B. AREA POLISHING RESULTS}

Area polishing results for three different samples now will be discussed. While the initial surfaces on Ti6Al4V were produced through micro end milling, the surfaces on Nickel and Al-6061-T6 were produced by abrasive media. They were polished using $650 \mathrm{~ns}$ laser pulses from a Nd:YAG laser at $1064 \mathrm{~nm}$ wavelength. The polishing was done at fluence values specific to each material.

\section{Nickel}

$\mathrm{PL} \mu \mathrm{P}$ was performed on a macro scale ground Nickel surface. A $500 \mu \mathrm{m} \times 500 \mu \mathrm{m}$ area was polished with the laser beam following a square zig-zag trajectory. The laser was pulsed at $4 \mathrm{kHz}$ corresponding to a pulse duration of $650 \mathrm{~ns}$. The maximum melt duration estimated using the two-dimensional heat transfer model is 994 ns (Table 2). This was used in Eq. (7) to predict the critical frequency, which was found to be $145 \mathrm{~mm}^{-1}$.

Table 2: Heat transfer model based estimations of maximum melt duration and critical frequency

\begin{tabular}{cccc}
\hline \hline Material & $\begin{array}{c}\text { Pulse duration, } \\
\mathbf{t}_{\text {pulse }}(\mathbf{n s})\end{array}$ & $\begin{array}{c}\text { Maximum melt } \\
\text { duration, } \\
\mathbf{t}_{\mathbf{m} \text {-max }}(\mathbf{n s})\end{array}$ & $\begin{array}{c}\text { Critical } \\
\text { frequency, } \\
\left.\mathbf{f}_{\mathbf{c r}} \mathbf{( m m}^{-1}\right)\end{array}$ \\
\hline $\begin{array}{c}\text { Stainless } \\
\text { steel 316L }\end{array}$ & 5000 & 6820 & 40 \\
Nickel & 650 & 994 & 145 \\
Ti6Al4V & 650 & 1164 & 115 \\
Al-6061-T6 & 650 & 2335 & 107 \\
\hline \hline
\end{tabular}

Figs. 7(a) and 7(b) show the 3D surface height data of the unpolished and polished regions $(350 \mu \mathrm{m} \times 265 \mu \mathrm{m})$ measured using the white light interferometer. Fig. 7(c) shows polished surface height data predicted using the proposed prediction methodology. Note that the measurements of unpolished surface height data and polished surface height data were made at different locations on the sample surface. This will not have a significant effect on the computation of the roughness parameters because the errors generally roughness parameters because the errors generally average out.

$\mathrm{S}_{\mathrm{a}}$ calculated from the measured surface height data reduced from an initial value of $191.3 \mathrm{~nm}$ to $146.8 \mathrm{~nm}$, while the proposed methodology predicts a final roughness of $130.6 \mathrm{~nm}$. The error in prediction can be partly attributed to the fact that the prediction is based on the unpolished surface height data which is measured at a different location than the polished surface height data. Fig. 8 shows the 2-D spectral content of the unpolished, polished and the predicted surfaces along with the critical frequency. Note that the amplitude of the frequencies above $\mathrm{f}_{\mathrm{cr}}$ is significantly reduced.

\section{Ti6Al4V}

The prediction methodology was next evaluated with micro end milled surfaces created on Ti6Al4V. The unpolished and polished surface height data were obtained using the white light interferometer [2]. The 3D surface heights are shown in Fig. 9 and the spatial frequency plots in Fig. 10. It can be seen that the predicted surface heights and the frequency spectrum closely matches the actual polished heights and the spectrum respectively. The maximum melt duration was estimated to be $1164 \mathrm{~ns}$ corresponding to $650 \mathrm{~ns}$ pulse duration (Table 2). The critical frequency was found to be $115 \mathrm{~mm}^{-1}$. Spatial filtering was performed with the estimated $\mathrm{f}_{\mathrm{cr}}$ as described in Step 3 of the prediction methodology. The initial average surface roughness was $181.2 \mathrm{~nm}$ and was reduced to $82.2 \mathrm{~nm}$ through $\mathrm{PL} \mu \mathrm{P}$. The average surface roughness was predicted to be $89.9 \mathrm{~nm}$ (see Table 3 ). Note again that the actual surface height profile is different from the predictions because the prediction is based on the unpolished surface profile, measured at a different location than the polished surface.

\section{Al-6061-T6}

The final material used to assess the proposed prediction methodology is Al-6061-T6. The initial surface was produced using macro scale grinding process resulting in an initial average roughness of $191.7 \mathrm{~nm}$. PL $\mu \mathrm{P}$ was carried out again at $650 \mathrm{~ns}$ long pulse and the maximum melt duration was estimated to be $2335 \mathrm{~ns}$. The critical frequency was found to be $107 \mathrm{~mm}^{-1}$. The roughness average of the polished surface calculated from the measured surface heights (Fig. 11(b)) is $130.8 \mathrm{~nm}$ while the prediction is $115 \mathrm{~nm}$. Fig. 11 shows 3-D surface heights of the measured unpolished and polished surfaces along with the predictions. Fig. 12 shows the spatial frequency spectra, obtained by 2-D Fourier transformation, of the unpolished and the unpolished surface height data from Fig. 11. Also shown is the filtered spatial frequency spectrum, which represents the frequency content predicted for the polished surface. Both the predicted surface heights and the frequency spectrum compare well with the surface heights and the corresponding frequency spectrum of the actual polished surface. 
(a) Original Sufface

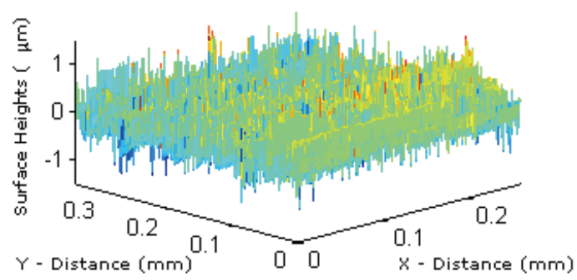

(b) Polished (Measured) Suface

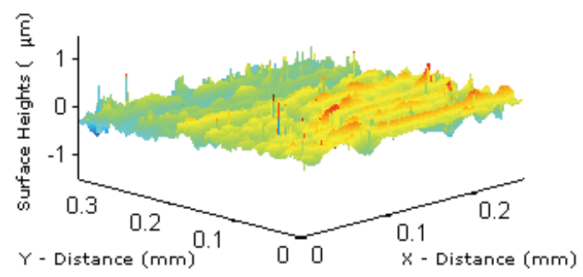

(c) Polished (Predicted) Surface
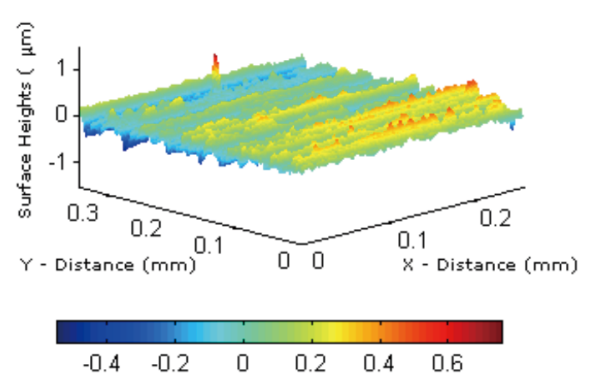

Fig. 7: Original unpolished, polished measured and polished predicted, 3-D surface height data of nickel
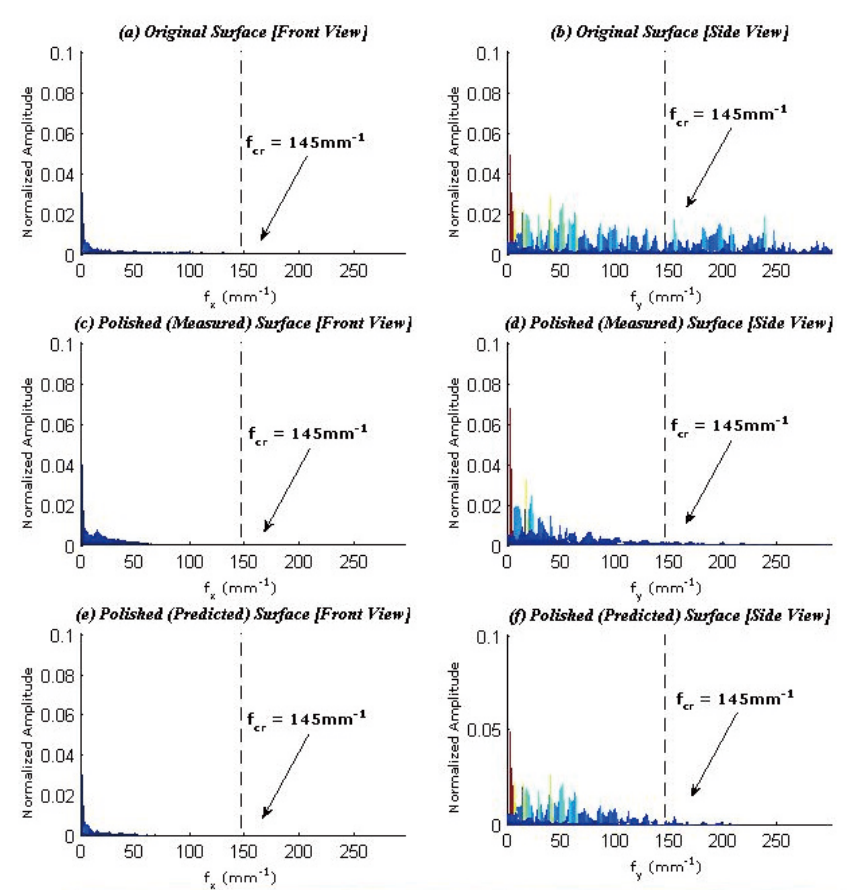

$\begin{array}{llllllllll}0.005 & 0.01 & 0.015 & 0.02 & 0.025 & 0.03 & 0.035 & 0.04 & 0.045 & 0.05\end{array}$

Fig. 8: 2-D spatial frequency plots of the original unpolished, polished measured and polished predicted surface on nickel (a) Original Suface

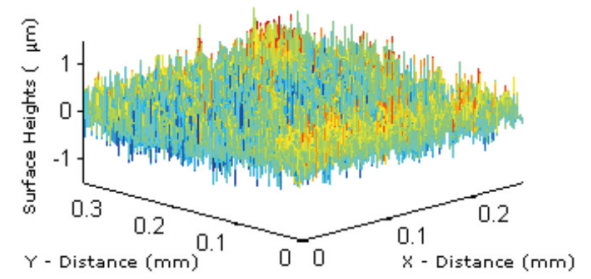

(b) Polished (Measured) Sufface

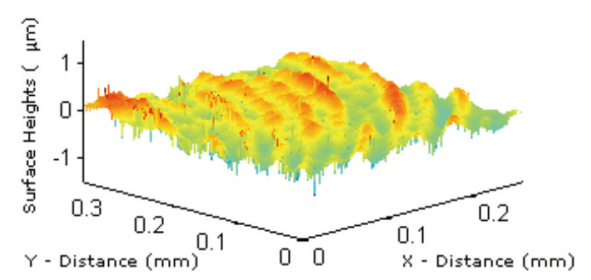

(c) Polished (Predicted) Sufface

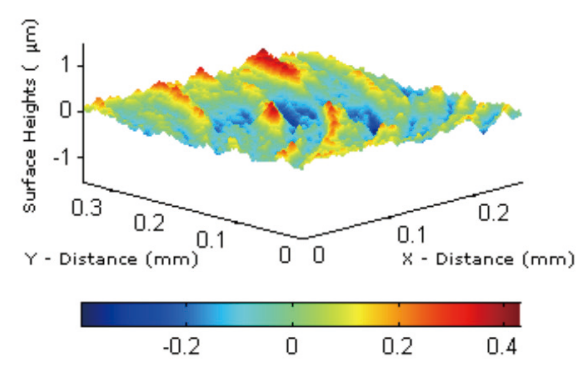

Fig. 9: Original unpolished, polished measured and polished predicted, 3-D surface height data of Ti6Al4V
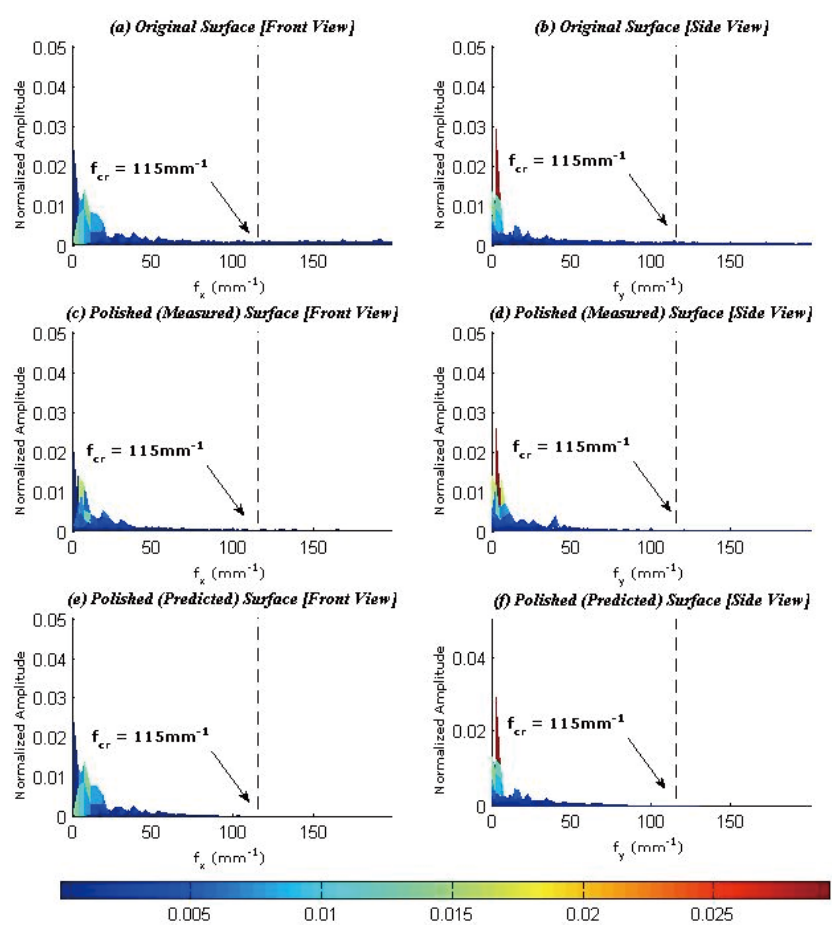

Fig. 10: 2-D spatial frequency plots of the original unpolished, polished measured and polished predicted surface on Ti6Al4V 


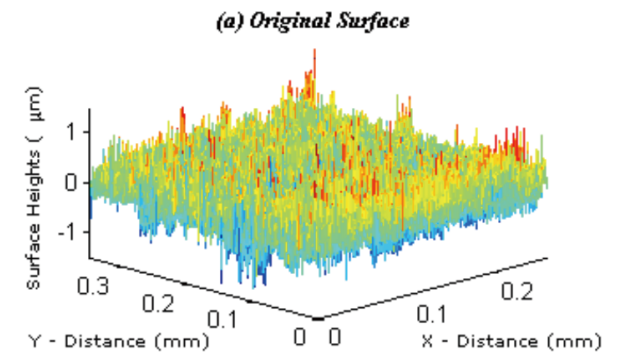

(b) Polished (Measured) Sufface

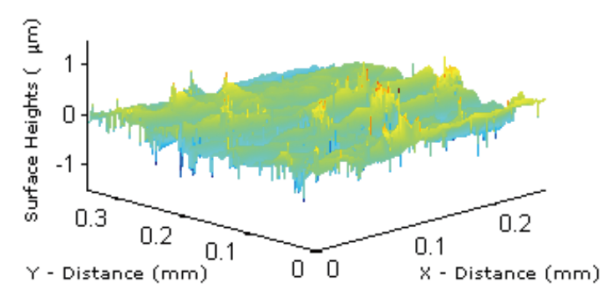

(c) Polished (Predicted) Suface

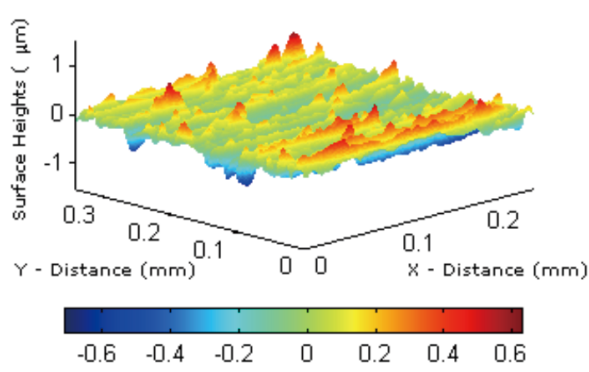

Fig. 11: Original unpolished, polished measured and polished predicted, 3-D surface height data of Al-6061-T6
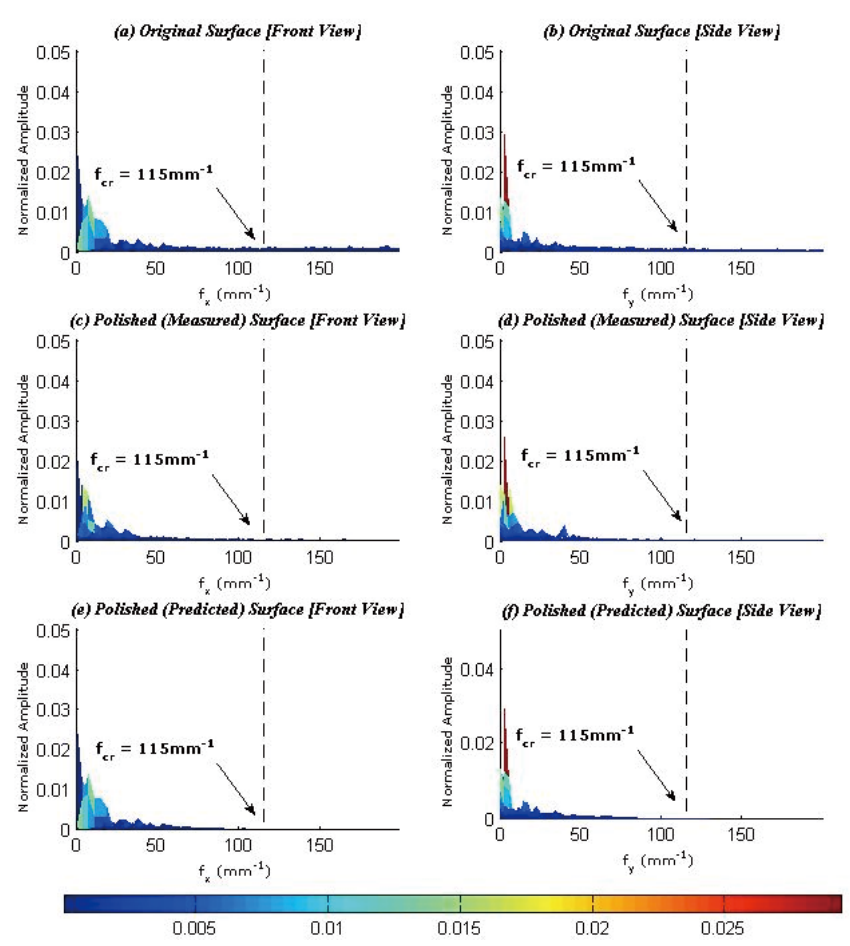

Fig. 12: 2-D spatial frequency plots of the original unpolished, polished measured and polished predicted surface on Al-6061-T6

\section{CONCLUSIONS}

An analytical fluid dynamic model for capillary waves and a numerical heat transfer model were developed and combined to predict the spatial frequency content of the surface resulting from $\mathrm{PL} \mu \mathrm{P}$ process, and also predict the resulting roughness. The prediction methodology was initially applied on surface line profiles and was validated on stainless steel. Later, it was evaluated, using 2-D Fourier analysis, for area finishing through PL $\mu \mathrm{P}$. The predictions were made on three different materials: Nickel, Ti6Al4V and Al-6061-T6. In each case, the roughness predicted for the polished surface was similar to the actual polishing results. In the case of Nickel, the roughness parameters were underestimated by approximately $16 \mathrm{~nm}$ corresponding to an error of $11 \%$, while Ti6Al4V roughness was overestimated by approximately $8 \mathrm{~nm}$, or $10 \%$. For Al-6061-T6, the roughness parameters were under-estimated by $10-15 \mathrm{~nm}$. This corresponds to an error of $12 \%$. These results indicate that the proposed prediction methodology can quickly and effectively predict polishing results for a variety of materials despite the numerous assumptions that are made.

Table 3: 2-D surface roughness parameters of unpolished, polished and predicted surfaces.

\begin{tabular}{cccc}
\hline \hline Material & Unpolished & Polished & Predicted \\
\hline \multicolumn{4}{c}{ Roughness average, $\mathrm{S}_{\mathrm{a}}(\mathrm{nm})$} \\
Nickel & 191.3 & 146.8 & 130.6 \\
Ti6A14V & 181.2 & 82.2 & 89.9 \\
Al-6061-T6 & 191.7 & 130.8 & 115.0 \\
\hline \multicolumn{4}{c}{ Root mean square roughness, $\mathrm{S}_{\mathrm{q}(\mathrm{nm})}$} \\
Nickel & 252.1 & 180.3 & 163.0 \\
Ti6A14V & 238.1 & 112.0 & 113.9 \\
Al-6061-T6 & 257.5 & 162.2 & 150.9 \\
\hline \hline
\end{tabular}

\section{AKNOWLEDGEMENTS}

This work was supported by NSF grant CMMI-0900044, NSF-supported shared facilities at the University of Wisconsin-Madison and LasX Industries, Inc. The authors would like to thank William Dinauer, Kevin Klingbeil, and Tyler Perry for their invaluable assistance with laser testing and control as well as their helpful discussions.

\section{REFERENCES}

[1] T. L. Perry, D. Werschmoeller, N. A. Duffie, X. C. Li, and F. E. Pfefferkorn, "Examination of Selective Pulsed Laser Micropolishing on Microfabricated Nickel Samples Using Spatial Frequency Analysis," Journal of Manufacturing Science and Engineering-Transactions of the Asme, vol. 131, no. 2, 2009.

[2] T. L. Perry, D. Werschmoeller, X. Li, F. E. Pfefferkorn, and N. A. Duffie, "Pulsed laser polishing of micro-milled Ti6Al4V samples," Journal of Manufacturing Processes, vol. 11, no. 2, 2009, pp. 74-81.

[3] T. L. Perry, D. Werschmoeller, X. C. Li, F. E. Pfefferkorn, and N. A. Duffie, "The Effect of Laser Pulse Duration and Feed Rate on Pulsed Laser Polishing of Microfabricated Nickel Samples," Journal of Manufacturing Science and Engineering-Transactions of the Asme, vol. 131, no. 3, 2009.

[4] T. Gietzelt, O. Jacobi, V. Piotter, R. Ruprecht, and J. Hausselt, 
"Development of a micro annular gear pump by micro powder injection molding," Journal of Materials Science, vol. 39, no. 6, 2004, pp. 2113-2119.

[5] S. Supriadi, E. R. Baek, C. J. Choi, and B. T. Lee, "Binder system for STS 316 nanopowder feedstocks in micro-metal injection molding," Journal of Materials Processing Technology, vol. 187, 2007, pp. 270-273.

[6] B. Y. Tay, L. Liu, N. H. Loh, S. B. Tor, Y. Murakoshi, and R. Maeda, "Surface roughness of microstructured component fabricated by [mu]MIM," Materials Science and Engineering A, vol. 396, no. 1-2, 2005, pp. 311-319.

[7] L. Liu, N. H. Loh, B. Y. Tay, S. B. Tor, Y. Murakoshi, and R. Maeda, "Effects of thermal debinding on surface roughness in micro powder injection molding," Materials Letters, vol. 61, no. 3, 2007, pp. 809-812.

[8] N. J. Hallab, K. J. Bundy, K. O'Connor, R. L. Moses, and J. J. Jacobs, "Evaluation of metallic and polymeric biomaterial surface energy and surface roughness characteristics for directed cell adhesion," Tissue Engineering, vol. 7, no. 1, 2001, pp. 55-71.

[9] P. F. Marella, D. B. Tuckerman, and R. F. Pease, "MODELING OF LASER PLANARIZATION OF THIN METAL-FILMS," Applied Physics Letters, vol. 54, no. 12, 1989, pp. 1109-1111.

[10] D. B. Tuckerman, and A. H. Weisberg, "Planarization of Gold and Alumunum Thin-Films using a Pulsed Laser," Ieee Electron Device Letters, vol. 7, no. 1, 1986, pp. 1-4.

[11] M. Bereznai, I. Pelsoczi, Z. Toth, K. Turzo, M. Radnai, Z. Bor, and A. Fazekas, "Surface modifications induced by ns and sub-ps excimer laser pulses on titanium implant material," Biomaterials, vol. 24, no. 23, 2003, pp. 4197-4203.

[12] A. Temmler, K. Graichen, and J. Donath, "Laser Polishing in Medical Engineering; Laser Polishing of Components for Left Ventricular Assist Devices," Laser Technik Journal, vol. 7, no. 2, 2010, pp. 53-57.

[13] Y. G. Kim, J. K. Ryu, D. J. Kim, H. J. Kim, S. Lee, B. H. Cha, H. Cha, and C. J. Kim, "Microroughness reduction of tungsten films by laser polishing technology with a line beam," Japanese Journal of Applied Physics Part 1-Regular Papers Short Notes \& Review Papers, vol. 43, no. 4A, 2004, pp. 1315-1322.

[14] T. A. Mai, and G. C. Lim, "Micromelting and its effects on surface topography and properties in laser polishing of stainless steel," Journal of Laser Applications, vol. 16, no. 4, 2004 , pp. 221-228.

[15] T. M. Shao, A. Hua, H. Y. Tam, and E. H. M. Cheung, "An approach to modelling of laser polishing of metals," Surface \& Coatings Technology, vol. 197, no. 1, 2005, pp. 77-84.

[16] J. Martan, O. Cibulka, and N. Semmar, "Nanosecond pulse laser melting investigation by IR radiometry and reflection-based methods," Applied Surface Science, vol. 253, no. 3 , 2006, pp. 1170-1177.

[17] W. E. Pendleton, G. P. Williams, R. T. Williams, J. C. Wu, G. B. Cvijanovich, J. L. Joyce, and M. McCleaf, "Scanning Tunneling Microscopy of Nickel Surface Features Before and After Rapid Melting by Excimer Laser," AMP Journal of Technology, vol. 3, 1993, pp. 75-84.

[18] K. Stout, and L. Blunt, Three-dimensional surface topography, Editor: 2000, pp. Pages.
[19] L. D. Landau, and E. M. Lifshits, Fluid mechanics, by L.D. Landau and E.M. Lifshitz, Editor: 1959, pp. Pages.

[20] V. N. Tokarev, and A. F. H. Kaplan, "An analytical modeling of time dependent pulsed laser melting," Journal of Applied Physics, vol. 86, no. 5, 1999, pp. 2836-2846.

[21] K. C. Mills, Recommended values of thermophysical properties for selected commercial alloys, Editor: 2002, pp. Pages.

[22] W. Zhang, C. H. Kim, and T. DebRoy, "Heat and fluid flow in complex joints during gas metal arc welding - Part I: Numerical model of fillet welding," Journal of Applied Physics, vol. 95, no. 9, 2004, pp. 5210-5219.

[23] M. Amara, V. Timchenko, M. El Ganaoui, E. Leonardi, and G. D. Davis, "A 3D computational model of heat transfer coupled to phase change in multilayer materials with random thermal contact resistance," International Journal of Thermal Sciences, vol. 48, no. 2, 2009, pp. 421-427.

[24] E. American Society of Mechanical, B. C. a. D. o. S. Q. American Society of Mechanical Engineers. Standards Committee, and I. American National Standards, Surface texture: surface roughness, waviness and lay, Editor: 2003, pp. Pages.

\section{APPENDIX A: PL $\mu$ P PARAMETERS}

\begin{tabular}{|c|c|c|}
\hline \multirow{8}{*}{ 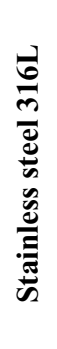 } & Type of laser & $\begin{array}{c}50 \mathrm{~W} \text { CW/Modulated } \\
\text { Fiber Laser }\end{array}$ \\
\hline & Initial surface & Micro end-milling \\
\hline & Pulse frequency $(\mathrm{kHz})$ & 20 \\
\hline & Pulse duration (ns) & 5000 \\
\hline & Spot size $(\mu \mathrm{m})$ & 30 \\
\hline & Pulse energy $(\mathrm{mJ})$ & 0.040 \\
\hline & Melt duration (ns) & 6820 \\
\hline & Critical frequency $\left(\mathrm{mm}^{-1}\right)$ & 40 \\
\hline \multirow{8}{*}{ 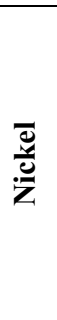 } & Type of laser & 250 W CW Nd:YAG \\
\hline & Initial surface & Macro scale grinding \\
\hline & Pulse frequency $(\mathrm{kHz})$ & 4 \\
\hline & Pulse duration (ns) & 650 \\
\hline & Spot size $(\mu \mathrm{m})$ & 60 \\
\hline & Pulse energy $(\mathrm{mJ})$ & 0.013 \\
\hline & Melt duration (ns) & 994 \\
\hline & Critical frequency $\left(\mathrm{mm}^{-1}\right)$ & 145 \\
\hline \multirow{8}{*}{ 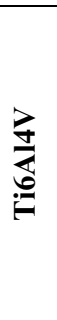 } & Type of laser & 250 W CW Nd:YAG \\
\hline & Initial surface & Micro end-milling \\
\hline & Pulse frequency $(\mathrm{kHz})$ & 4 \\
\hline & Pulse duration (ns) & 650 \\
\hline & Spot size $(\mu \mathrm{m})$ & 60 \\
\hline & Pulse energy $(\mathrm{mJ})$ & 0.036 \\
\hline & Melt duration (ns) & 1164 \\
\hline & Critical frequency $\left(\mathrm{mm}^{-1}\right)$ & 115 \\
\hline \multirow{8}{*}{$\begin{array}{l}0 \\
0 \\
\frac{1}{2} \\
0 \\
0 \\
0 \\
\frac{1}{4}\end{array}$} & Type of laser & 250 W CW Nd:YAG \\
\hline & Initial surface & Macro scale grinding \\
\hline & Pulse frequency $(\mathrm{kHz})$ & 4 \\
\hline & Pulse duration (ns) & 650 \\
\hline & Spot size $(\mu \mathrm{m})$ & 60 \\
\hline & Pulse energy $(\mathrm{mJ})$ & 0.171 \\
\hline & Melt duration (ns) & 2335 \\
\hline & Critical frequency $\left(\mathrm{mm}^{-1}\right)$ & 107 \\
\hline
\end{tabular}

